\title{
Modeling Bare Ground With Classification Trees in Northern Spain
}

\author{
Keith T. Weber, ${ }^{1}$ Concepción L. Alados, ${ }^{2}$ C. Guillermo Bueno, ${ }^{3}$ Bhushan Gokhale, ${ }^{4}$ \\ Benjamin Komac, ${ }^{5}$ and Yolanda Pueyo ${ }^{6}$
}

\begin{abstract}
Authors are ${ }^{1}$ GIS Director and ${ }^{4} \mathrm{PhD}$ Candidate, Idaho State University, GIS Training and Research Center, 921 S 8th Avenue, Stop 8104, Pocatello, ID 83209-8104, USA; ${ }^{2}$ Doctor, Consejo Superior de Investigaciones Científicas, Instituto Pirenaico de Ecología, Avenida Montañana 1005, PO Box 13034, 50192 Zaragoza, Spain; ${ }^{3}$ PhD Candidate, Consejo Superior de Investigaciones Científicas, Instituto Pirenaico de Ecología, Avenida Regimiento Galicia S/ N, PO Box 64, 22700 Jaca, Spain; ${ }^{5}$ PhD Candidate, Consejo Superior de Investigación Científica, Instituto Pirenaico de Ecología, Avenida Montañana 1005, PO Box 202, 50192 Zaragoza, Spain; and ${ }^{6}$ Doctor, University of Zaragoza, Department of Geography, Pedro Cerbuna, 12, 50009 Zaragoza,
\end{abstract} Spain.

\begin{abstract}
Bare ground abundance is an important rangeland health indicator and its detection is a fundamental part of range management. Remote sensing of bare ground might offer solutions for land managers but also presents challenges as modeling in semiarid environments usually involves a high frequency of spectral mixing within pixels. Classification tree analysis (CTA) and maximum likelihood classifiers were used to model bare ground in the semiarid steppes of the middle Ebro valley, Aragon, Spain using Satellite Pour l'Observation de la Terre 4 (SPOT 4) imagery and topographic data such as elevation, slope, aspect, and a morphometric characterization model. A total of 374 sample points of bare-ground fraction from sixteen $500-\mathrm{m}$ transects were used in the classification and validation process. Overall accuracies were $85 \%$ (Kappa statistic $=0.70$ ) and $57 \%$ (Kappa statistic $=0.13)$ from the CTA and maximum likelihood classifiers, respectively. Although spectral attributes were essential in bare-ground classification, the topographic and morphometric properties of the landscape were equally critical in this modeling effort. Although the specific layers best suited for each specific model will vary from region to region, this study provided an important insight on both bare-ground modeling and the potential advantages of CTA.
\end{abstract}

\section{Resumen}

La cantidad de suelo desnudo es un indicador importante del estado de los pastizales y su cuantificación es una parte fundamental para el manejo de los mismos. La medición por medio de sensores remotos del suelo desnudo puede ofrecer soluciones a los usuarios de este recurso y al mismo tiempo representa un reto dado que su modelización en ambientes semiáridos implica una alta frecuencia de mezclas espectrales en los píxeles. Se han empleado tanto análisis de árboles de clasificación (CTA) como clasificadores de máxima verosimilitud para modelar el suelo desnudo en los pastizales semiáridos del valle medio del Ebro en Aragón, España. Se usaron imágenes del "Satellite Pour l'Observation de la Terre 4" (SPOT 4) y datos topográficos tales como elevación, pendiente, orientación, y un modelo de caracterización morfométrica. Un total de 374 puntos de muestreo, provenientes de dieciseis transectos de la fracción de suelo desnudo, se usaron en los procesos de clasificación y validación. La exactitud total fue un $85 \%(\mathrm{Kappa}=0.70)$, y un $57 \%(\mathrm{Kappa}=0.13)$ respectivamente para el análisis de árboles de clasificación y de máxima verosimilitud. Mientras que los atributos espectrales fueron esenciales en la clasificación del suelo desnudo, las propiedades topográficas y morfométricas del paisaje fueron igualmente críticas en el esfuerzo de modelización. Aunque las capas específicas que mejor se ajustan a cada modelo CTA varían de una región a otra, este estudio proporciona un importante avance en la modelización de suelo desnudo y en la potencial utilidad del CTA.

Key Words: classification tree analysis, desertification, geographic information systems (GIS), rangelands, remote sensing

\section{INTRODUCTION}

Rangeland ecosystems cover approximately $40 \%$ of the earth's terrestrial surface (Branson et al. 1981; Huntsinger and Hopkinson 1996) and are typically dominated by grass and shrub communities. These vegetation communities exist because of the semiarid or xeric nature of these sites. However, an effective hydrologic cycle (the capture, storage, and release of water) leads to healthy rangeland sites that produce green

Research was funded by a grant from the National Aeronautics and Space Administration Goddard Space Flight Center (NNX06AE47G).

Correspondence: Keith T. Weber, GIS Director, Idaho State University, GIS Training and Research Center, 921 S 8th Avenue, Stop 8104, Pocatello, ID 83209-8104, USA. Email: webekeit@isu.edu

Manuscript received 20 May 2009; manuscript accepted 8 July 2009. biomass (at least ephemerally) with minimal bare ground. The green biomass is effectively used by herbivores (e.g., livestock), which are an integral part of a functional rangeland ecosystem. When the hydrologic cycle is disturbed, rangelands desertify, and as a result, exhibit increasing amounts of bare-ground exposure. Chronic desertification shifts lead to a loss of ecosystem functionality, a reduction in biodiversity, and reduced livestock grazing capabilities (Daubenmire 1959; Schlesinger et al. 1990) with associated social and economic underpinnings (Savory 1999; Arnalds and Archer 2000; Griffin et al. 2001).

The degree of bare ground is a reliable indicator of rangeland health within otherwise similar regions (National Research Council 1994; Whitford et al. 1998; Pyke et al. 2002; Booth and Tueller 2003; Hunt et al. 2003; O'Brien et al. 2003). One of the consequences of sedenterization of livestock is the exceedingly high loss of plant cover and plant biomass. 
Although stocking rate can be relatively low, the way livestock use the landscape can have important consequences on triggering land degradation processes. Indeed, in spite of an average reduction of stocking rate in many areas of the world, recent increases in animal number per farm is leading to higher degradation around shelters (Alados et al. 2006).

Remote sensing provides a means to detect bare ground at various scales and continuous extents with multitemporal capabilities (Booth and Tueller 2003; Palmer and Fortescue 2003; Washington-Allen et al. 2006). However, bare-ground detection is challenging because of the high frequency of spectral mixing within pixels, which is a function of image resolution relative to the size of the vegetation canopy and the distribution and arrangement of plants within a study area. Even when using the highest spatial resolution multispectral satellite imaging sensor (Quickbird 2.4-m pixels) pixels will nearly always be comprised of various fractions of shrub, grass, litter, and bare ground, etc. Although high spatial resolution aerial imagery has been able to minimize or reduce mixed pixels (Booth and Cox 2008) it does not capture spectral reflectance data and often is fraught with georectification problems, leading to numerous challenges and limitations as well (Moffet 2009).

Previous work in sagebrush-steppe rangelands suggests that bare ground can be reliably detected (overall accuracy $=87 \%$ ) when bare ground is $\geq 50 \%$ (Gokhale and Weber 2006). Where bare ground is less common $(<25 \%)$, it becomes increasingly difficult to accurately model, and classification accuracies are typically much lower.

This paper describes a study where classification tree analysis (CTA) and maximum likelihood classification were used to model bare-ground fraction in northern Spain. CTA is a nonprobabilistic, nonparametric statistical technique wellsuited to modeling skewed, nonnormal data and phenomena (Friedl and Brodley 1997; Breiman et al. 1998; Lawrence and Wright 2001; Miller and Franklin 2001). It is hypothesized that bare ground is nonnormally distributed, and for this reason, can be modeled more accurately with CTA relative to other supervised classification techniques. The CTA algorithms select useful spectral and ancillary data that optimally reduce divergence in a response variable (Lawrence and Wright 2001) such as bare-ground exposure. CTA uses machine learning to perform binary recursive splitting operations and ultimately yields a classification tree diagram that is used to produce a model of the response variable. Splitting algorithms common to CTA include entropy, gain ratio, and Gini. The entropy algorithm has a tendency to over-split, creating an unnecessarily complex tree (Zambon et al. 2006). The gain ratio algorithm addresses the over-splitting problem through normalization whereas the Gini algorithm partitions the most homogeneous clusters first using a measure of impurity while isolating the largest homogenous category from the remainder of the data (McKay and Campbell 1982; Zambon et al. 2006). As a result, classification trees developed using the Gini splitting algorithm are less complex and therefore more easily understood by the analyst. For these reasons, the Gini splitting algorithm was selected for use in this study.

A key advantage of CTA is its ability to use both spectral and nonspectral data selectively during the splitting and classification process. This allows for the use of topographic data, which can be equally important in modeling bare ground. Such ancillary data can be used with other supervised classification techniques (Lillesand et al. 2008) but classifiers such as maximum likelihood use all input data to arrive at a final classification. This is in contrast to the advantage of CTA noted above, which selectively applies input data in its classification process.

\section{MATERIALS AND METHODS}

\section{Study Area}

This study focuses upon the xeric steppes of the middle Ebro valley, Aragon, Spain and is referred to as the Monegros study area (Fig. 1). The dominant plant species in the area is rosemary (Rosmarinus officinalis L.) with various gypsophile plant species over a gypsum substrate in the most xeric areas. Scattered remnants of the original juniper-woodland community (Juniperus thurifera L.) also are present. The study area covers over 300000 ha $\left(3000 \mathrm{~km}^{2}\right)$ with the valley receiving the majority of its water from the Pyrenees Mountains, yet it is a dry area with low precipitation $(<0.30 \mathrm{~m}$ annually).

Grazing activity in the area consisted of various flocks of sheep grazed under a semiextensive regimen. Specifically, livestock were led by a shepherd to graze the fallow fields and rangeland steppe continuously throughout the year. Flocks were moved daily from shelters to the surrounding grazing areas where they stayed from morning until evening. Supplementary food was provided during the driest season and for reproductive females. Livestock productivity in the area is low, with an estimated stocking rate of $0.2 \mathrm{head} \cdot \mathrm{ha}^{-1} \cdot \mathrm{yr}^{-1}$ (Pueyo et al. 2008).

\section{Satellite Imagery}

Satellite Pour l'Observation de la Terre 4 (SPOT 4) collects data in four spectral bands from the visible $(545-\mathrm{nm}$ band center [green] and $645-\mathrm{nm}$ band center [red]) through near-infrared (NIR; 840-nm band center) and short-wave infrared (SWIR; $1665-\mathrm{nm}$ band center) portions of the electromagnetic spectrum. These data are stored as raster imagery having a spatial resolution of $20 \mathrm{~m} \times 20 \mathrm{~m}$. One SPOT 4 image was acquired on 11 May 2007 for use in this study. The SPOT 4 data were processed to top-of-the-atmosphere reflectance using the $\operatorname{Cos}(\mathrm{t})$ image-based correction method (Chavez 1988) in Idrisi Andes software (Clark Labs, Worcester, MA). The imagery was then georectified (root mean square error $[\mathrm{RMSE}]=8.3 \mathrm{~m}$ ) using $0.5 \mathrm{~m} \times 0.5 \mathrm{~m}$ aerial photography and projected into Universal Transverse Mercator (zone 30N, European datum 1950) using a first-order affine transformation and nearest neighbor resampling.

In addition to the atmospherically corrected SPOT 4 bands (1-4), a normalized difference vegetation index (NDVI), moving standard deviation index (MSDI; Tanser 1997; Tanser and Palmer 1999), principal components analysis (PCA) layers, and biomass estimates (Mirik et al. 2005) also were calculated within Idrisi Andes using SPOT reflectance data to develop a predictive model of bare ground for the Monegros study area.

The biomass layer is a simple ratio-type vegetation index where reflectance values from the short-wave infrared region (band) are divided by reflectance values from the green band. 


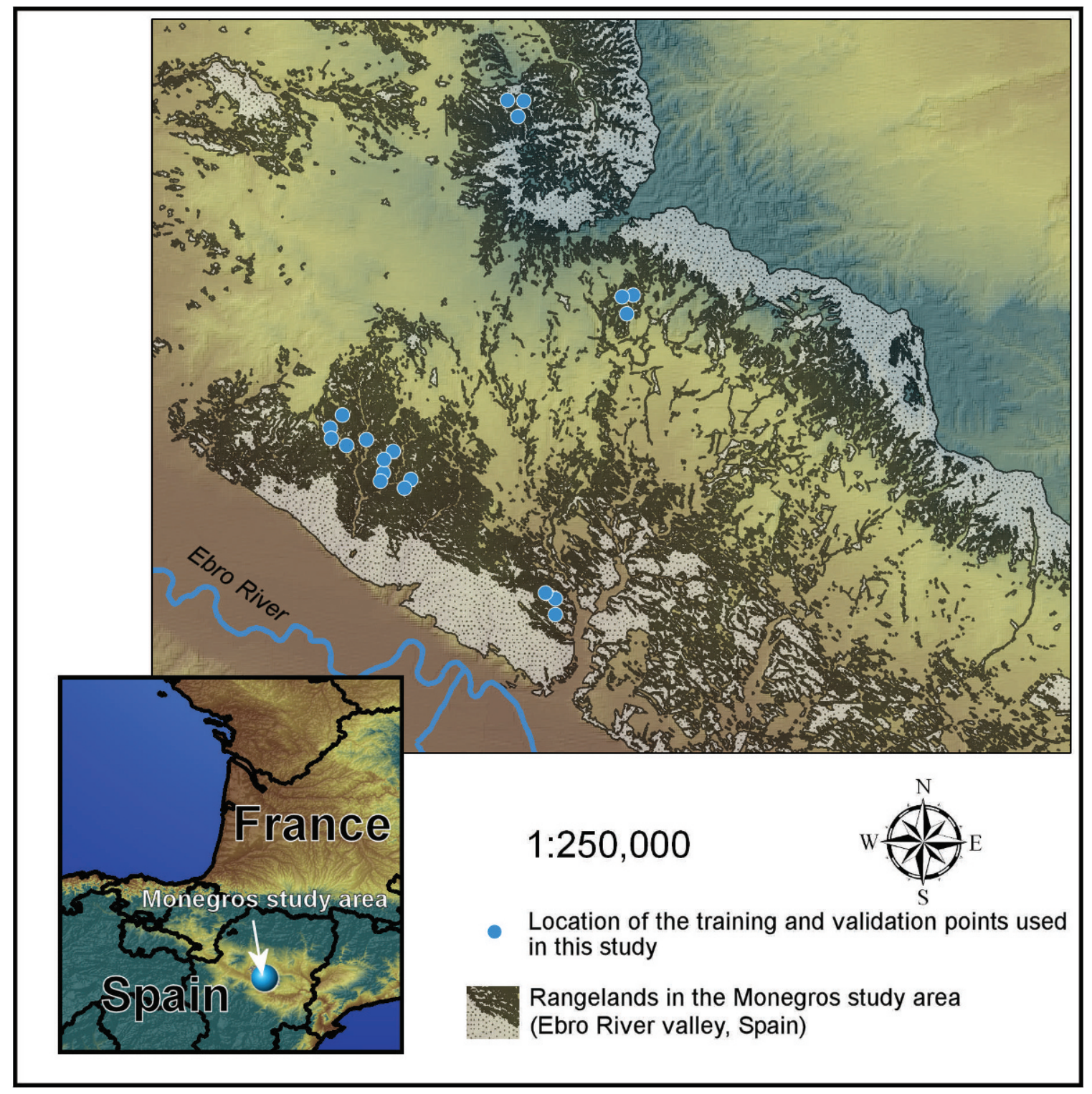

Figure 1. The Monegros study area in northern Spain. Note: due to scale, each individual sample point cannot be shown.

The resulting layer is an index and pixel values were not expressed in physical units. Although Mirik et al. (2005) demonstrated a strong empirical relationship $\left(R^{2}=0.87\right)$ between this index and actual standing crop biomass on rangelands, the relationship of the biomass index with actual above ground rangeland biomass at the Monegros study area was not performed as part of this study.

\section{Topographic Data}

A digital elevation model $(20 \mathrm{~m} \times 20 \mathrm{~m}$ pixels; $\mathrm{RMSE}=7.42$; Pueyo 2005) for the Monegros study area was acquired from the Confederación Hidrográfica Del Ebro (http://oph.chebro. es/ContenidoCartografico.htm). Slope (expressed in degrees) and aspect models were calculated in Idrisi Andes and a model of morphometric characterization (i.e., valley, ridge, pass, or flat) was developed using LandSerf software (Wood 1996). These topographic data (elevation, slope, aspect, and mor- phometry) were used to develop a predictive model of bareground exposure.

\section{Field Sampling}

To estimate bare ground at the Monegros study area, sixteen 500-m transects were acquired between 17 May and 24 May 2004. The start location of each transect was recorded using global positioning systems (GPS) with eight transects located on north-facing slopes and eight transects located on southfacing slopes. Observations were made every $0.2 \mathrm{~m}$ along each transect that described the cover type (plant species or bare ground) at that point (Gysel and Lyan 1980; Herrick et al. 2005). Percent bare ground was calculated for each 20-m segment of each transect and $\mathrm{X}$ - and Y-coordinates determined for the location of each segment. As each transect was oriented in an east-west direction, the Y-coordinate remained constant along each transect line. The X-coordinate for each segment 
Table 1. Classification tree analysis results for bare-ground modeling in the Monegros study area in northern Spain. Overall accuracy $=0.85$; overall Kappa index of agreement $=0.70$.

\begin{tabular}{lcccc}
\hline \multirow{2}{*}{ Model results } & \multicolumn{3}{c}{ Known validation sites } & User \\
\cline { 2 - 4 } & Bare-ground & Nonbare-ground & Total & accuracy \\
\hline Bare ground & 29 & 8 & 37 & 0.79 \\
Nonbare ground & 1 & 22 & 23 & 0.96 \\
Total & 30 & 30 & 60 & \\
Producer's accuracy & 0.97 & 0.74 & & \\
\hline
\end{tabular}

was determined by incrementing the beginning X-coordinate ( $\pm 10 \mathrm{~m}$ to shift the point to the center of the first line segment) by $20 \mathrm{~m}$ and repeating this process until the end of each transect was reached. Percent bare ground for each $20 \mathrm{~m}$ segment was subsequently represented as a point feature $(n=397)$ in all future analyses.

In May 2008, an additional 42 points were collected using GPS ( $\pm 0.3 \mathrm{~m}, 95 \%$ confidence interval [CI]), which described bare ground only. Three bare-ground classes were used: minimal $(\sim \leq 10 \%)$, moderate $(\sim 10-50 \%)$, and high $(\sim \geq 50 \%)$ with percent bare ground determined ocularly. All GPS locations were differentially corrected to minimize positioning error and improve coregistration among the data used in this study (Weber et al. 2008).

Although two methods were used to collect field sample data, these methods were considered complementary by the authors. Similarly, both McMahan et al. (2003) and Norton (2008) reported that these methods are applicable for ground truthing purposes, especially where estimates are made at nadir and categorical cover classes are used to support image processing of remotely sensed data.

\section{Data Preparation}

All field sample locations $(n=439)$ were classified as either 1$)$ a bare-ground site (having $\geq 50 \%$ bare-ground fraction; $n=129$ ); 2) a nonbare-ground site (having $\leq 10 \%$ bare ground, $n=65$ ); or 3) an intermediate site with $10-50 \%$ $(n=245)$ bare ground. Only bare-ground and nonbare-ground sample locations $(n=194)$ were used to develop the model because they effectively represented pure end-members. Sixty field sample locations were randomly selected using Hawth's tools in Environmental Systems Research Institute's ArcGIS and reserved as validation sites with $50 \%$ of the points selected from each class (bare ground and nonbare ground). The remaining locations were used as training sites $(n=134)$. The training and validation point shape files were imported into Idrisi Andes and rasterized using the same spatial parameters as the satellite imagery and topography layers described above (e.g., $20 \times 20 \mathrm{~m}$ pixels).

\section{Image Processing and Accuracy Assessment}

Spectral signatures for bare-ground and nonbare-ground training sites were extracted from all satellite imagery layers and examined for signature seperability. Most layers indicated some potential for separation between bare-ground and nonbare-ground sites save for PCA bands 2 and 3, which were subsequently removed from future analysis.
Table 2. Maximum likelihood results for bare-ground modeling in the Monegros study area in northern Spain. Overall accuracy $=0.57$; overall Kappa index of agreement $=0.13$.

\begin{tabular}{lcccc}
\hline & \multicolumn{3}{c}{ Known validation sites } & User \\
\cline { 2 - 4 } \multicolumn{1}{c}{ Model results } & Bare-ground & Nonbare-ground & Total & accuracy \\
\hline Bare ground & 25 & 21 & 46 & 0.54 \\
Nonbare ground & 5 & 9 & 14 & 0.64 \\
Total & 30 & 30 & 60 & \\
Producer's accuracy & 0.83 & 0.30 & & \\
\hline
\end{tabular}

CTA was performed in Idrisi Andes using the Gini splitting algorithm (Zambon et al. 2006) with twelve input layers available for the classification process: green, red, NIR, and SWIR reflectance bands, NDVI and biomass band-ratios, MSDI band filter, PCA band one, and elevation, slope, aspect, and morphometry topography layers. Output included the resulting tree and a classified predictive model of bare ground with all pixels assigned one of two values: 1) bare-ground site and 2) nonbare-ground site. For comparison, a maximum likelihood classification was performed using spectral signatures from the same twelve input layers. Accuracy was assessed using a standard error matrix (Congalton 1991; Congalton and Green 2009), which reported user's accuracy, producer accuracy, overall accuracy, and the Kappa index of agreement statistic (Cohen 1960; Titus et al. 1984; Foody 1992; Monserud and Leemans 1992). Both error matrices were compared using Kappa and the variance of Kappa following Congalton and Green (2009) by calculating a pairwise Zstatistic.

$$
Z_{\text {pairwise }}=\left|K_{1}-K_{2}\right| / \sqrt{\operatorname{var}\left(K_{1}\right)+\operatorname{var}\left(K_{2}\right)}
$$

where $K_{1}$ and $K_{2}$ are the Kappa statistics for error matrices 1 and 2 and $\operatorname{var}\left(\mathrm{K}_{1}\right)$ and $\operatorname{var}\left(\mathrm{K}_{2}\right)$ are estimates of variance for matrices 1 and 2 . The $Z_{\text {pairwise }}$ critical value at the $95 \%$ CI is 1.96.

\section{RESULTS AND DISCUSSION}

CTA classification yielded an overall accuracy of $85 \%$, user's accuracy of $79 \%$, and producer accuracy of $97 \%$ for the bareground class (Table 1). The bare-ground model had an overall Kappa Index of Agreement of 0.70 and a Kappa Index of Agreement of 0.91 for the bare-ground class alone. The Kappa scores indicate that the classification performed far better than a chance classification.

Results of the maximum likelihood classification yielded an overall accuracy of $57 \%$, user's accuracy of $54 \%$, and producer accuracy of $83 \%$ for the bare-ground class (Table 2). The Kappa score (0.13) indicates this classification performed only marginally better than a chance classification. Although the same input layers, training sites, and validation sites were used for both classifications, CTA performed much better than the more traditional maximum likelihood classifier $\left(Z_{\text {pairwise }}=\right.$ 4.43; $Z_{\text {critical }}=1.96$ ). The observed difference in performance likely is attributable to the way in which maximum likelihood functions with respect to the input layers the software is 


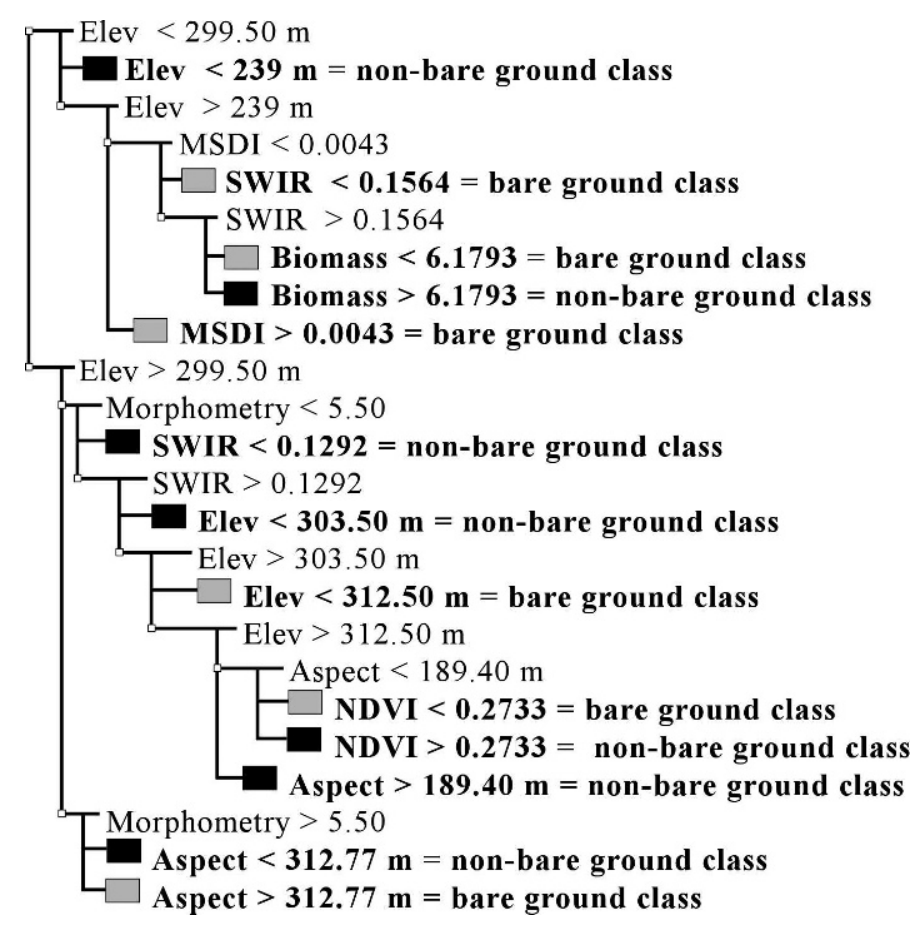

Figure 2. Classification tree produced for the bare-ground model. Bold text is used to indicate where a final class decision was made: gray boxes indicate bare-ground class; black boxes, nonbare-ground class (bare-ground sites were defined as having $\geq 50 \%$ bare ground).

provided by the user. Maximum likelihood uses the spectral signature from all input layers to determine the output class of each pixel. As a result, some input layers may confuse the classifier and result in poor overall performance. This confusion is suggested in Table 2 by the model over-committing pixels to the bare-ground class.

In contrast, CTA can be given many input layers initially, but after running its splitting algorithm the final model might be based upon only a fraction of those layers. Subsequently, classification tree (Fig. 2) can offer insight into the classification process by allowing the analyst to study what was identified as an indicator layer. In this instance, none of the raw imagery bands were selected for use in the classification with the exception of the SWIR band. In addition, the principal components layer was not used as well as the slope layer. The initial split chosen by the Gini algorithm was based upon elevation $(\sim 300 \mathrm{~m})$ where the elevation in the Monegros study area ranged from $137 \mathrm{~m}$ to $805 \mathrm{~m}($ mean $=354 \mathrm{~m})$. Within the lower elevation areas, MSDI was used but was not selected for use in the higher elevation areas. In the lower elevation areas, higher MSDI values were more indicative of a bare-ground site than a nonbare-ground site, which agrees with Tanser and Palmer (1999), who reported that degraded or unstable areas exhibited higher MSDI values. SWIR reflectance was used to make two splits in the tree with the selected threshold values occurring at relatively low values (approximately 0.16 and 0.13 , where the minimum value in the layer was 0.003 and the maximum value was 0.347$)$ and below the mean $(0.18)$. The biomass layer also was used by the Gini algorithm but was selected only within the low elevation branch of the tree. Here, low-biomass values $(<6.2)$ were indicative of bare-ground sites

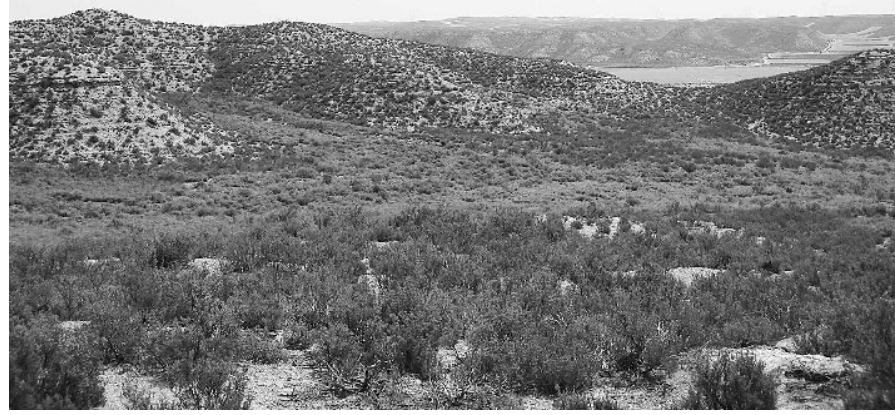

Figure 3. A photograph of the Monegros study area illustrating the effect of landscape morphometry on bare-ground exposure. Very little bare ground exists in the flat areas (morphometry $=6$ ) whereas much higher proportions of bare ground were found on the adjacent hilly sites. This phenomenon was captured by the classification tree and used to improve the final model (cf. Fig. 2).

whereas all higher values were indicative of nonbare-ground sites $($ mean $=6.9)$.

Apart from the initial split that used the elevation layer, no topographic layers were used to arrive at a final classification for the lower elevation sites $38.8 \%$ of the Monegros study area). Instead, spectral information was used to finalize the classification of these areas. In contrast, the Gini algorithm used numerous topographic layers along with two spectral layers to classify the higher elevation areas $(61.2 \%$ of the Monegros study area) including aspect (where westerly and northwesterly sites were more indicative of nonbare-ground areas) and morphometry layers. One explanation for the increased number of variables used to classify bare ground above $300 \mathrm{~m}$ is the gradual increase in patch heterogeneity found in these areas. This is related to a higher proportion of residual forest and shrub land patches along the elevational gradient. The upper elevation areas were traditionally less used by local inhabitants because more favorable farming and grazing areas were found at lower elevations closer to the Ebro River. In most parts of the study area human activities such as timber harvesting, farming, and grazing have been intensively developed for centuries (Pueyo and Alados 2007). The result is these long-term anthropic disturbances have led to fragmented secondary communities that are very sensitive to aridity, and more directly related to past human activities than environmental factors (Pueyo and Alados 2007).

The morphometry layer played an important role in the classification of higher elevation sites. Albeit a simple model, the morphometry layer described each pixel in the study area as either valley $(2[23 \%])$, pass $(3[3 \%])$, ridge $(4[24 \%])$, or flat (6 [5\%]). During the classification, all values $>5.5$ (i.e., flat areas) were differentiated from nonflat areas and then further split and classified using other layers. This corroborates well with field observations (Fig. 3) where it was noted that the least 
amount of bare ground tended to be found in the flat areas between or at the foot of hills. These areas are sink sites and the result of where sediment and litter were exported from the hill top to the foot of the hill (Bilbro and Fryrear 1994; Belnap and Gillette 1998). As a result, soil fertility has increased, which favors the growth of a vegetation community dominated by rhizomatous grasses (Guerrero-Campo et al. 1999). In contrast, the slopes have been more desiccated by wind (Aguiar and Sala 1999), yielding more xeric conditions. In these higher elevation sites, NDVI and SWIR were the only spectral layers used with lower NDVI values $(<0.27)$ indicative of bare-ground sites.

To further interpret the model, the 245 sample points previously removed from the classification process because they did not represent pure end-members (i.e., bare ground ranged from $10-50 \%$ ) were cross-tabulated with the bare-ground model. Similar in process to that described for the preparation of training and validation points, this shape file was rasterized for use in Idrisi Andes. As a result, 190 pixels were used in the cross-tabulation with 114 pixels $(60 \%)$ falling into areas considered bare ground and 76 pixels $(40 \%)$ falling into areas considered nonbare ground. Based upon field transect data, the mean bare ground at these sites was $31 \%$, suggesting that bareground detection might be possible at levels below 50\%. However, when additional CTA iterations were performed using training sites with bare ground $\geq 33 \%$, classification accuracy decreased to $49 \%$ overall accuracy with a Kappa of only 0.03. This result suggests a bare-ground detection threshold exists and a minimum of $50 \%$ bare ground is required to produce a model with reliable accuracies (i.e., $>75 \%$ overall accuracy; Goodchild et al. 1994).

CTA outperformed maximum likelihood $(85 \%$ and $57 \%$ overall accuracy, respectively) in this study and produced classification accuracy results equivalent to those reported by Gokhale and Weber (2006; 87\% overall accuracy). The previous study however, used Quickbird imagery (2.4-m pixels) whereas the present study accomplished comparable accuracies using 20-m pixels (SPOT 4). This provides a distinct advantage relative to cost-effectiveness and for the aerial extent covered by a single scene $(\sim 16.5 \mathrm{~km} \times 16.5 \mathrm{~km}$ Quickbird; $\sim 60 \mathrm{~km}$ $\times 60 \mathrm{~km}$ SPOT 4). These results suggest a need for additional research to learn more about the effect of spatial resolution on classification accuracy.

The results of this research indicate that CTA can be a valuable technique for the detection of bare ground in semiarid rangelands where bare ground is $\geq 50 \%$, especially when applied at landscape scales. Semiarid ecosystems like the Monegros study area frequently exhibit plant cover $<60 \%$ (Aguiar and Sala 1999) and the plant cover/bare-ground fraction can change rapidly in response to disturbance. In these areas, detection of bare ground exceeding $50 \%$ can be beneficial to land managers as an early detection technique for land degradation and unsustainable use. Although livestock grazing is common in the Monegros, stocking rate was considered relatively low (Pueyo 2005). However, the existing grazing management predisposes the areas near shelters to overuse as flocks frequent those pastures every day both before and after movement to/from the grazing areas. Although daily movements of animals were typically $<3 \mathrm{~km}$ from shelters, the detection of bare ground in these areas is important for the management of critical water resources, which can otherwise trigger serious desertification processes.

CTA might have performed better than more traditional classifiers such as maximum likelihood, because each branch and each leaf of the classification tree can use raster layers that might or might not have been used to finalize other branches or leaves of the same tree. This gives CTA the capability to fit a solution to each unique classification problem. In addition, while numerous input layers are available to the classifier, the classifier is not programmatically required to use each available layer. Rather, CTA will use only those layers offering optimal splitting. The user can then study the resulting tree to learn more about the landscape he/she is analyzing, and in this way, CTA becomes a highly interactive human-machine learning system.

The results presented here do not imply that the best way to model bare ground is with those layers selected for this classification. Rather, one important result presented in this paper is the application of CTA for bare-ground modeling and potentially other complex detection applications.

\section{MANAGEMENT IMPLICATIONS}

Where bare ground exceeds $50 \%$, CTA appears to be a classification technique appropriate for modeling bare ground in semiarid rangelands. The results presented in this paper are similar to those reported by Gokhale and Weber (2006) where Quickbird imagery and maximum likelihood classification was used for bare-ground detection.

Although spectral data were essential to this model, of equal importance were the topographic and morphometric characteristics of the landscape. This finding lends insight to both bare-ground modeling and the potential capabilities of CTA. The results presented here should not be interpreted as the only way to model bare ground, but rather, CTA should be viewed as a powerful and flexible classification technique applicable to bare-ground modeling with potential for application to other complex detection applications.

\section{ACKNOWLEDGMENTS}

Idaho State University would like to acknowledge the Idaho Delegation for their assistance in obtaining this grant. In addition, the study would not have been possible without the collaboration and cooperation of Consejo Superior de Investigaciones Cientificas (CSIC) and in particular, the Instituto Pirenaico de Ecologia (IPE).

\section{LITERATURE CITED}

Aguiar, M. R., and O. E. Sala. 1999. Patch structure, dynamics and implications for the functioning of arid ecosystems. Trends in Ecology and Evolution 14:273-277.

Alados, C. L., A. El Aich, V. Papanastasis, H. Ozbek, and H. Freitas. 2006. Monitoring tools to assess vegetation successional regresión and predict catastrophic shifts and desertification in Mediterranean rangelands ecosystems. In: W. Kepner, J. L. Rubio, D. Mouat, and F. Pedrazzini [EDS.]. Desertification in the Mediterranean region. A security issue. NATO Security Through Science Series, Volume 3. Dordrecht, The Netherlands: Springer. p. 431-449. 
Arnalds, O., and S. Archer. 2000. Rangeland desertification. Dordrecht, Netherlands: Kluwer Academic Publishers. 209 p.

Belnap, J., And D. A. Gillette. 1998. Vulnerability of desert biological soil crusts to wind erosion: the influences of crust development, soil texture, and disturbance. Journal of Arid Environments 39:133-142.

Bilbro, J. D., and D. W. Fryrear. 1994. Wind erosion losses as related to plant silhouette and soil cover. Agronomy Journal 86:550-553.

Booth, D. T., AND S. E. Cox. 2008. Image-based monitoring to measure ecological change in rangelands. Frontiers in Ecology and the Environment 6(4):185-190.

Booth, D. T., ANd P. T. Tueller. 2003. Rangeland monitoring using remote sensing. Arid Lands Research and Management 17:455-467.

Branson, F. A., G. F. Gifford, K. G. Renard, and R. F. Hadley. 1981. Evaporation and transpiration. In: E. H. Reid [ED.]. Rangeland hydrology. Range Science Series 1. 2nd ed. Denver, CO, USA: Society for Range Management. p. 179-200.

Breiman, L., J. H. Friedman, R. A. Olshen, and C. J. Stone. 1998. Classification and regression trees. Boca Raton, FL, USA: Chapman and Hall/CRC Press. $358 p$.

Chavez, P. S. 1988. An improved dark-object subtraction technique for atmospheric scattering correction of multispectral data. Remote Sensing of Environment 24:459-479.

COHEN, J. 1960. A coefficient of agreement for nominal scales. Educational and Psychological Measurement 20:37-46.

Congalton, R. G. 1991. A review of assessing the accuracy of classifications of remotely sensed data. Remote Sensing of Environment 37:35-46.

Congalton, R. G., and K. Green. 2009. Assessing the accuracy of remote sensed data: principles and practices. Boca Raton, FL, USA: CRC Press. 183 p.

Daubenmire, R. 1959. A canopy-coverage method of vegetation analysis. Northwest Science 33:43-64.

Foody, G. M. 1992. On the compensation for chance agreement in image classification accuracy assessment. Photogrammetric Engineering and Remote Sensing 58:1459-1460.

FriedL, M. A., ANd C. E. Brodley. 1997. Decision tree classification of land cover from remotely sensed data. Remote Sensing of Environment 61:399-409.

GoKHALE, B., AND K. T. WeBER. 2006. Rangeland health modeling with Quickbird imagery. In: K. T. Weber [ED.]. Final report: detection prediction, impact, and management of invasive plants using GIS. Pocatello, ID, USA: Idaho State University. p. 3-16.

Goodchild, M. F., G. S. Biging, R. G. Congalton, P. G. Langley, N. R. Chrisman, and F. W. Davis. 1994. Final report of the accuracy assessment task force. California Assembly Bill AB1580. University of California, Santa Barbara, CA, USA: National Center for Geographic Information and Analysis (NCGIA).

Griffin, D. W., C. A. Kellogg, and E. A. Shinn. 2001. Dust in the wind: Iong range transport of dust in the atmosphere and its implications for global public and ecosystem health. Global Change \& Human Health 2:20-33.

Guerrero-Campo, J., F. Alberto, J. Hodgson, J. M. García Ruiz, and G. Montserrat MarTí. 1999. Plant community patterns in a gypsum area of ne Spain. Interactions with topographic factors and soil erosion. Journal of Arid Environments 41:401-410.

GySEL, L. W., AND L. J. LyAn. 1980. Habitat analysis and evaluation. In: S. D. Schemnitz [ED.]. Wildlife management techniques manual, 4th ed. Revised. Washington, DC, USA: Wildlife Society. p. 305-317.

Herrick, J. E., J. W. Van Zee, K. M. Havstad, L. M. Burkett, and W. G. Whitford. 2005. Monitoring manual for grassland, shrubland, and savanna ecosystems. Volume II: design, supplementary methods, and interpretation. Tucson, AZ, USA: University of Arizona Press. 200 p.

Hunt, E. R., J. H. Everitt, J. C. Ritchie, M. S. Moran, D. T. Booth, G. L. Anderson, P. E. Clark, and M. S. Seyfried. 2003. Applications and research using remote sensing for rangeland management. Photogrammetric Engineering and Remote Sensing 69:675-693.

HunTSINGER, L., AND P. HoPKINSON. 1996. Viewpoint: sustaining rangeland landscapes: a social and ecological process. Journal of Range Management 49:167-173.

Lawrence, R. L., and A. Wright. 2001. Rule-based classification systems using classification and regression tree (CART) analysis. Photogrammetric Engineering and Remote Sensing 67:1137-1142.

Lillesand, T. M., R. W. Kiefer, AND J. W. Chipman. 2008. Remote sensing and image interpretation. 6th ed. Hoboken, NJ, USA: John Wiley and Sons. 756 p.
McKay, R. J., and N. A. Campbell. 1982. Variable selection techniques in discriminant analysis. II: Allocation. British Journal of Mathematical and Statistical Psychology 35:30-41.

McMahan, B., D. Narsavage, and K. T. Weber. 2003. The pole-cam: corroborating field estimations with high spatial resolution imagery. In: K. T. Weber [ED.]. Final report: wildfire effects on rangeland ecosystems and livestock grazing in Idaho. Pocatello, ID, USA: Idaho State University. p. 18-23.

Miller, J., AND J. Franklin. 2001. Modeling the distribution of four vegetation alliances using generalized linear models and classification trees with spatial dependence. Ecological Modeling 157:227-247.

Mirik, M., J. E. Norland, R. L. Crabtree, and M. E. Biondini. 2005. Hyperspectral one-meter-resolution remote sensing in Yellowstone National Park, Wyoming. II: Biomass. Rangeland Ecology \& Management 58:459-465.

Moffet, C. A. 2009. Agreement between measurements of shrub cover using ground-based methods and very large scale aerial imagery. Rangeland Ecology \& Management 62:269-277.

Monserud, R., and R. LeEmans. 1992. Comparing global vegetation maps with the kappa statistic. Ecological Modeling 62:275-293.

National Research Council. 1994. Rangeland health: new methods to classify, inventory, and monitor rangelands. Washington, DC, USA: National Academy Press. 180 p.

NoRton, J. 2008. Comparison of field methods. In: K. T. Weber [eD.]. Final report: Impact of temporal landcover changes in southeastern Idaho rangelands (NNG05GB05G). Pocatello, ID, USA: Idaho State University. p. 41-50.

O'Brien, R. A., C. M. Johnson, A. M. Wilson, and V. C. Elsbernd. 2003. Indicators of rangeland health and functionality in the Intermountain West. US Department of Agriculture, Rocky Mountain Research Station. General Technical Report RMRS-GTR-104. Available at: http://www.fs.fed.us/rm/pubs/rmrs_gtr104.pdf 20pp. Accessed 10 July 2009.

Palmer, A. R., and A. Fortescue. 2003. Remote sensing and change detection in rangelands. In: N. Allsopp, A. R. Palmer, S. J. Milton, K. P. Kirkman, G. I. H. Kerley, and C. R. Hurt [EDS.]. Proceedings of the VII International Rangelands Congress, Durban, South Africa. Irene, South Africa: Document Transformation Technologies. p. 675-680.

PueYo, Y. 2005. Evaluación de los factores ambientales y del uso antrópico como condicionantes de la conservación de la vegetación del sector central de la depresión del Ebro [dissertation]. Zaragoza, Spain: University of Zaragoza. $291 \mathrm{p}$.

Puevo, Y., and C. L. Alados. 2007. Effects of fragmentation, abiotic factors and land use on vegetation recovery in a semi-arid Mediterranean area. Basic and Applied Ecology 8:158-170.

Pueyo, Y., C. L. Alados, O. Barrantes, B. Komac, and M. Rietkerk. 2008. Differences in gypsum plant communities associated with habitat fragmentation and livestock grazing. Ecological Applications 18:954-964.

Pyke, D. A., J. E. Herrick, P. Shaver, and M. Pellant. 2002. Rangeland health attributes and indicators for qualitative assessment. Journal of Range Management 55:584-597.

Savory, A. 1999. Holistic management: a new framework for decision making. Washington, DC, USA: Island Press. 616 p.

Schlesinger, W. H., J. F. Reynolds, G. L. Cunningham, L. F. Huenneke, W. M. Jarrell, R. A. Virginia, And W. G. Whitford. 1990. Biological feedbacks in global desertification. Science 247:1043-1048.

TANSER, F. C. 1997. The application of a landscape diversity index using remote sensing and geographical information systems to identify degradation patterns in the Great Fish River Valley, Eastern Cape Province, South Africa [thesis]. Grahamstown, South Africa: Rhodes University. 167 p.

Tanser, F. C., and A. R. Palmer. 1999. The application of a remotely-sensed diversity index to monitor degradation patterns in a semi-arid, heterogeneous, South African landscape. Journal of Arid Environments 43:477-484.

Titus, K., J. A. Mosher, And B. K. Williams. 1984. Chance-corrected classification for use in discriminant analysis: ecological applications. The American Midland Naturalist 111:1-7.

Washington-Allen, R. A., N. E. West, R. D. Ramsey, and R. E. Efroymson. 2006. A prototcol for retrospective remote sensing-based ecological monitoring on rangelands. Rangeland Ecology \& Management 59:19-29. 
Weber, K. T., J. Theau, and K. Serr. 2008. Effect of coregistration on patchy target detection using high-resolution imagery. Remote Sensing of Environment 112:845-850.

Whitford, W. G., A. G. De Soyza, J. W. Van Zee, J. E. Herrick, and K. M. Havstad. 1998. Vegetation, soil, and animal indicators of rangeland health. Environmental Monitoring Assessment 51:179-200.
Wood, J. D. 1996. The geomorphological characterisation of digital elevation models [thesis]. Leicester, United Kingdom: University of Leicester. 185 p. Available at: http://www.soi.city.ac.uk/ jwo/phd. Accessed 21 July 2008.

Zambon, M., R. Lawrence, A. Bunn, and S. Powell. 2006. Effect of alternative splitting rules on image processing using classification tree analysis. Photogrammetric Engineering and Remote Sensing 72:25-30. 